\section{Leaf Anatomy of Apple Trees during Seasonal Periods under Subtropical Conditions}

\author{
Guilherme Locatelli, Rafael Pio, Rayane Barcelos Bisi, \\ Filipe Bittencourt Machado de Souza, \\ Mariana Thereza Rodrigues Viana, and Daniela da Hora Farias \\ Departamento de Agricultura, Universidade Federal de Lavras, Lavras, $M G$, \\ 37200-000, Brazil
}

\section{Evaristo Mauro de Castro \\ Departamento de Biologia, Universidade Federal de Lavras, Lavras, MG, 37200-000, Brazil}

\section{Carolina Ruiz Zambon \\ Departamento de Agricultura, Universidade Federal de Lavras, Lavras, MG, 37200-000, Brazil}

Additional index words. Malus domestica, optical microscopy, scanning electron microscopy, water deficit

\begin{abstract}
Water deficits are considered the primary environmental stress in agriculture, and improving the growth and production of plants under this stress is one of the primary goals of breeding and crop management programs. The apple tree is a plant that is negatively affected by water stress. Plants that develop under a water deficit may develop physiological and anatomical strategies to survive or even produce fruits in these environments. In view of the importance of and lack of studies of the leaf anatomy of apple trees in areas with a water deficit that are intended to support genetic improvement programs for this fruit either to introduce cultivars in regions with water deficits or to select potential progenies for future crosses, the aim of this study was to compare the anatomical characteristics of apple leaves from two distinct environments (water deficit and precipitation) under tropical conditions. Twelve fully expanded leaves were collected from seven apple cultivars (Eva, Rainha, Princesa, Julieta, Imperatriz, Baronesa, and Gala Real), which are planted in the experimental orchard at Universidade Federal de Lavras, during water deficit (September) and precipitation (February) seasons. Sixteen anatomical characteristics were evaluated in addition to the anatomical description of the apple leaves. The experimental design was completely randomized in a $7 \times 2$ factorial arrangement. The means were analyzed using the Scott-Knott method for grouping means at the $5 \%$ level of error probability. Genetic divergence, cultivar clustering and principal component analyses were also performed based on the anatomical characteristics evaluated during the two seasons. The apple leaves had anatomical characteristics that can favor the production of this fruit tree in areas experiencing water deficits within subtropical regions. According to their anatomical characteristics, there was genetic divergence among the apple cultivars studied here. The cultivars Gala Real, Eva, and Baronesa presented anatomical and morphological characteristics that showed adaptation potential in areas with water deficits.
\end{abstract}

Water deficits are considered the primary environmental stress in agriculture, and improving the growth and production of plants under this stress is one of the primary goals of breeding and crop management programs

Received for publication 9 May 2019. Accepted for publication 2 Aug. 2019.

We thank UFLA, Coordenação de Aperfeiçoamento de Pessoal de Nível Superior (CAPES) Brazil (Finance Code 001), Conselho Nacional de Desenvolvimento Científico e Tecnológico $(\mathrm{CNPq})$, and FAPEMIG (Fundação de Amparo à Pesquisa do Estado de Minas Gerais) for the financial support for research.

D.d.H.F. is the corresponding author. E-mail: dhorafarias@gmail.com.
(Cattivelli et al., 2008; Queiroz-Voltan et al., 2014). Cultivating apple trees (Malus domestica) in environments with water deficits affects the apple mass, thus reducing production (Ebel et al., 2001). Biochemical changes can also occur in leaves under water deficit conditions, thereby triggering changes during the initial stages and leading to an increase in the concentration of protective substances (oxidizing substances) (Sircelj et al., 2005). Almond trees grown under water deficit conditions develop several adaptive mechanisms such as osmotic adjustment, changes in the elastic properties of cells and tissues, foliar abscission, stomatal regulation, and a deep root system (Oliveira et al., 2018).
Another peculiarity of plants that grow under water deficit is the development of strategies that allow the plants to perform photosynthesis. One significant strategy is the reduction of the cellular osmotic potential (Batista et al., 2010) through the accumulation of liquid solutes (Morgan 1984; Wright et al., 1997). This mechanism results in the maintenance of cell turgor and the opening of the stomata, allowing the plant to accumulate solutes such as carbohydrates, amino acids, and organic acids (Chartzoulakis et al., 1999; Nunes et al., 1989).

In addition to physiological and biochemical changes, the leaves of the plants under water deficit undergo morphological changes. Changes in the leaf blade area, such as the increased thickening of the cuticle, the adaxial and abaxial epidermis, and the palisade and spongy parenchyma, are evidence that plants can respond adaptively to different environments (Batista et al., 2010; Bosabalidis; Kofidis, 2002; Castanheira et al., 2016; Grisi et al., 2008; Oliveira et al., 2018; QueirozVoltan et al., 2014).

Many authors have performed morphological studies primarily of leaves, which are fast-adapting organs, to assist in their selection of cultivars, progenies, or accessions of different species to adapt to water deficits. The results have shown that these changes can be inherited (Batista et al., 2010; Bosabalidis; Kofidis, 2002; Castanheira et al., 2016; Grisi et al., 2008; Oliveira et al., 2018; Queiroz-Voltan et al., 2014; Viana et al., 2018). In fact, one of the main characteristics evaluated for the description of leaves of plants for adaptation to the water deficit involves the stomatal properties and water relations (Zokaee-Khosroshahi et al., 2014). Analyses of genetic diversity through multivariate techniques have been used in breeding programs to assist in assessing genetic predispositions (Azevedo et al., 2013; Ivoglo et al., 2008; Moreira et al., 2009).

Changes in the internal structures of apple leaves in areas with water deficits are important. To assist early pre-breeding programs in introducing cultivars in water deficit regions or in selecting potential progeny for future crosses, the aim of this study was to compare the anatomical characteristics of apple leaves from two different environments (water deficit and precipitation) under tropical conditions.

\section{Materials and Methods}

This experiment was performed in 2016 and 2017 on seven 7-year-old apple cultivars (Eva, Rainha, Princesa, Julieta, Imperatriz, Baronesa, and Gala Real) grafted on Marubakaido rootstock with M9 filter. The apple trees were arranged in randomized blocks corresponding to four blocks with three plants of each cultivar per block. The study area has a subtropical climate, and it is located in the Lavras municipality of Minas Gerais state in Brazil $\left(21^{\circ} 14^{\prime} \mathrm{S}, 45^{\circ} 00^{\prime} \mathrm{W}\right)$. The regional climate is classified as Cwa 
(subtropical with dry winter), which is characterized by hot, humid summers and dry, cold winters (Alvares et al., 2013). The soil is classified as Dystrophic Red-Yellow Latosol. During the experiment, the mean monthly precipitation and temperature data were collected (Fig. 1).

During the experiment, leaf samples were prepared from the epidermal surfaces of all the treatments (apple cultivars) for scanning electron microscopy. For this purpose, fragments of the abaxial surface from the middle regions of the leaves from each cultivar were fixed separately in modified Karnovsky's fixative (2.5\% glutaraldehyde and $2.5 \%$ formaldehyde in $0.05 \mathrm{M}$ sodium cacodylate buffer, $\mathrm{pH} 7.2$, $0.001 \mathrm{M} \mathrm{CaCl}_{2}$ ), postfixed in $1 \%$ osmium tetroxide solution, and dehydrated in solutions with increasing acetone concentrations (30\%, $50 \%, 70 \%, 90 \%$, and $100 \%$ ).

Subsequently, the samples were critical point-dried with liquid $\mathrm{CO}_{2}$ in a Balzers (Model CPD 030) apparatus, then mounted on aluminum stubs and coated with gold (Balzers SCD 050 evaporator) for observation using a scanning electron microscope (LEO, model EVO 40). The electron microscopy images were generated and digitally recorded to be analyzed later.

For the quantitative anatomical studies of the leaves, 12 fully expanded leaves were collected from the middle one-third of the plants from each cultivar. In the laboratory, the leaves were collected at random (three leaves from each accession), and each leaf was considered a replicate. Two collections were taken, with one during the water deficit season in Sept. 2016, and another during the precipitation season in Feb. 2017.

The leaves were fixed in 70\% FAA solution (formaldehyde, acetic acid, and 70\% ethyl alcohol at a 1:1:18 ratio). After $72 \mathrm{~h}$, the leaves were placed in a new 70\% alcohol solution $\left(\mathrm{v} \cdot \mathrm{v}^{-1}\right)$ to preserve the material
(Johansen, 1940). Next, 0.25- $\mathrm{cm}^{2}$ fragments were collected from the middle region of the leaf blade and from the midrib; they were dehydrated in an ethanol series and embedded in Leica hydroxyethyl methacrylate (Wetzlar, Germany) according to the manufacturer's protocol. After the fragments were embedded, $8-\mu \mathrm{m}$ cross-sections were obtained using a rotary microtome; they were stained with $1 \%$ Toluidine Blue and mounted on slides with $50 \%$ glycerine (Kraus and Arduin, 1997).

Paradermic sections of the abaxial epidermis, which were taken from the leaf middle region, were obtained using a steel blade. The sections were subsequently cleared in $50 \%$ sodium hypochlorite solution, washed in distilled water, stained with $1 \%$ safranin, and mounted in 50\% glycerol (Kraus and Arduin, 1997). At that stage, three slides per leaf were prepared and three fields of view per slide were evaluated using an objective lens with $20 \times$ magnification. Then, the slides were observed and photographed under an Olympus BX 60 optical microscope coupled to a Canon A630 digital camera to capture the images.

The images were analyzed with software for measuring anatomical parameters to evaluate the following in the cross-sections of the leaf blade: the thickness of the abaxial epidermis (ABE); thickness of the adaxial epidermis (ADE); thickness of the adaxial cuticle (ADC); thickness of the palisade parenchyma (PAP); thickness of the spongy parenchyma (SPP); and thickness of the leaf blade (TLB). For the leaf midrib, the following parameters were evaluated: the xylem area (XA); phloem area (FA); number of xylem vessels (NXV); the diameter of the xylem vessels (DXV); xylem thickness (XYT); and phloem thickness (FLT). In the paradermic sections, the following parameters were analyzed: the stomatal density (DEN) (number of stomata per $\mathrm{mm}^{2}$ ); polar diameter

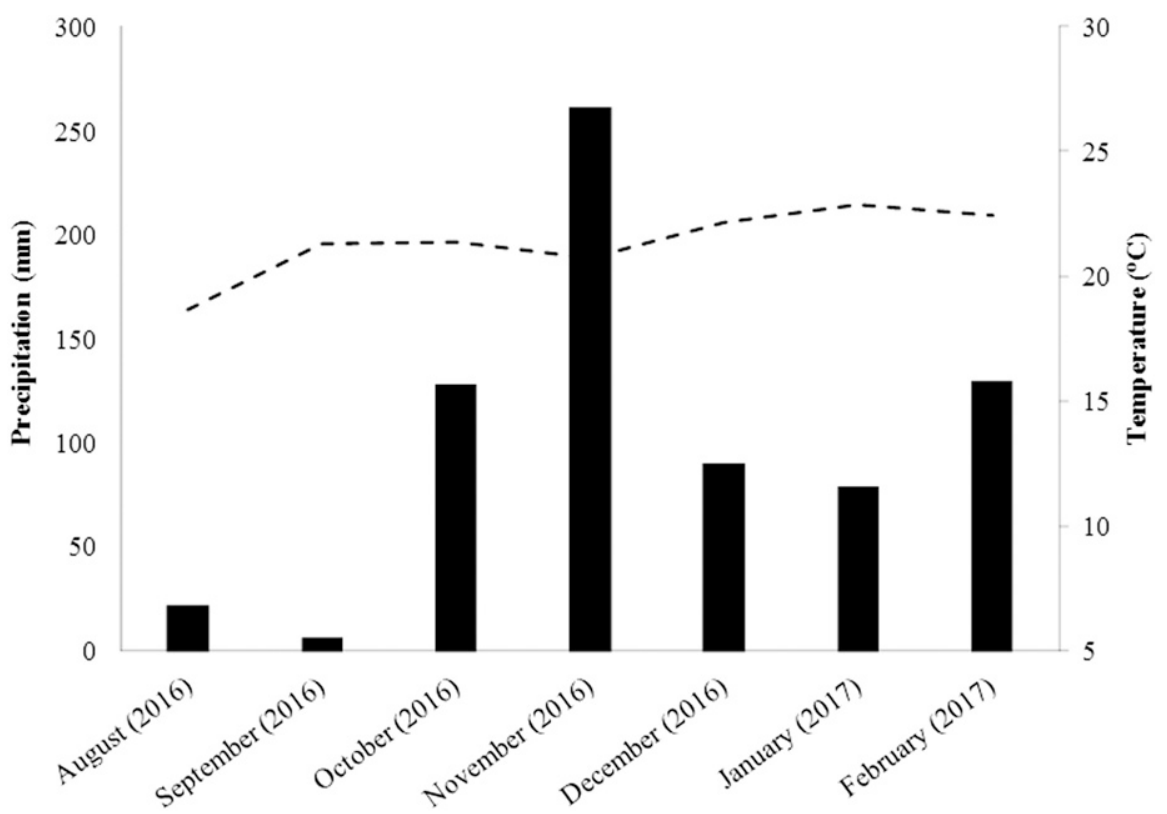

Fig. 1. Mean monthly precipitation and temperature during the experimental period. of the stomata (POD); and equatorial diameter of the stomata (EQD). These yielded the stomatal functionality (FUN) (polar diameter/ equatorial diameter of stomata).

An analysis of variance (ANOVA) was performed by considering a completely randomized design with a $7 \times 2$ factorial arrangement ( 7 cultivars $\times 2$ seasons, water deficit and precipitation) with three replicates. After the ANOVA, the means were analyzed using the Scott-Knott method of grouping means at a $5 \%$ probability of error.

To quantify the divergence between accessions, a dissimilarity measure was obtained based on the Gower (1971) algorithm. With the dissimilarity measures, a cluster analysis was performed using the hierarchical unweighted pair-group method using an arithmetic mean (UPGMA) method. To test the efficiency of the hierarchical clustering method, the cophenetic correlation coefficient (CCC) was estimated according to the methodology described by Sokal and Rohlf (1962). The cut-off point of the UPGMA dendrogram was defined according to Mojena (1977). In addition to the other multivariate methods, the principal component analysis was used to assess the diversity among the accessions. According to Cruz et al. (2004), this method is characterized by displaying the importance of the functions in decreasing order; the initial function expresses the maximum variance between the groups of cultivars that have formed. All the analyses were performed using the genetic and statistical computational application genes (Cruz, 2013).

\section{Results and Discussion}

Even though there were no statistically significant differences, the area occupied by the transport vessels (the xylem and phloem) varied, even within the same cultivar, as evidenced by the high values of variance (Table 1). Environmental factors did not influence the xylem and phloem area. The mean xylem area of the seven cultivars during the precipitation season was $8.17 \times 10^{4} \mu^{2}$; during the water deficit season, it was $7.91 \times 10^{4}$ $\mu \mathrm{m}^{2}$. The same trend occurred for the phloem area; coincidentally, the mean value of the cultivars during the precipitation season $\left(8.46 \times 10^{4} \mu \mathrm{m}^{2}\right)$ was higher than that of the water deficit season $\left(7.83 \times 10^{4} \mu \mathrm{m}^{2}\right)$. Oliveira et al. (2018) compared the leaf anatomy of commercial and traditional almond cultivars (Prunus dulcis) under water deficit, and they observed great variation in the area occupied by transport vases within the same cultivars. However, they also found differences between the evaluated cultivars, which did not occur in the present study.

Regarding xylem thickness (Table 1), in the water deficit season, the cultivars Princesa, Imperatriz, and Gala Real obtained the highest tissue thickness at $157.23,164.84$, and $171.80 \mu \mathrm{m}$, respectively. However, during the precipitation season, there was no variation in the xylem thickness in the different cultivars. Similar results were found by Queiroz-Voltan 
et al. (2014) because the thickening of the vascular bundles allows for greater flows of elaborated sap, water, and mineral salts during the water deficit season, thus providing these plants with favorable adaptive characteristics under water stress conditions.

Regarding the phloem thickness, there was no difference between the seasons or cultivars undergoing study, except for the Baronesa cultivar, which exhibited greater phloem thickness under precipitation conditions (Table 1). Normally, there is greater thickening of this tissue when the plant is subjected to water deficit, as observed by Queiroz-Voltan et al. (2014) when working with different coffee cultivars. Medri et al. (2011) also found no difference in the phloem thickness of Aegiphila sellowiana Cham. (Lamiaceae) when the plant was subjected to substrate flooding.

Regarding the number of xylem vessels, there were differences between the cultivars of the water deficit season; Baronesa and Gala Real showed higher numbers of vessels (303.33 and 338.89, respectively) than the other cultivars under water deficit conditions. Gala Real also displayed a higher number of xylem vessels under water deficit conditions than under precipitation conditions (Table 1).
All the cultivars presented xylem vessels with larger diameters during the precipitation season than during the water deficit season, with the exception of the Imperatriz cultivar, which did not exhibit differences between the two seasons. After the water deficit season, the Imperatriz cultivar had a larger vessel diameter of $13.41 \mu \mathrm{m}$ (Table 1).

Normally, when plants are subjected to a water deficit and demonstrate an adaptive capacity, it is expected that the number of xylem vessels has increased and the diameter of these vessels has been reduced to prevent embolisms due to this stress, which may hinder water transport by the plant. Carlquist

Table 1. Xylem area (XA), phloem area (FA), xylem thickness (XYT), phloem thickness (FLT), number of xylem vessels (NXV), and diameter of xylem vessels (DXV) in apple cultivars as estimated during the precipitation season (February) and the water deficit season (September) in 2016 and 2017.

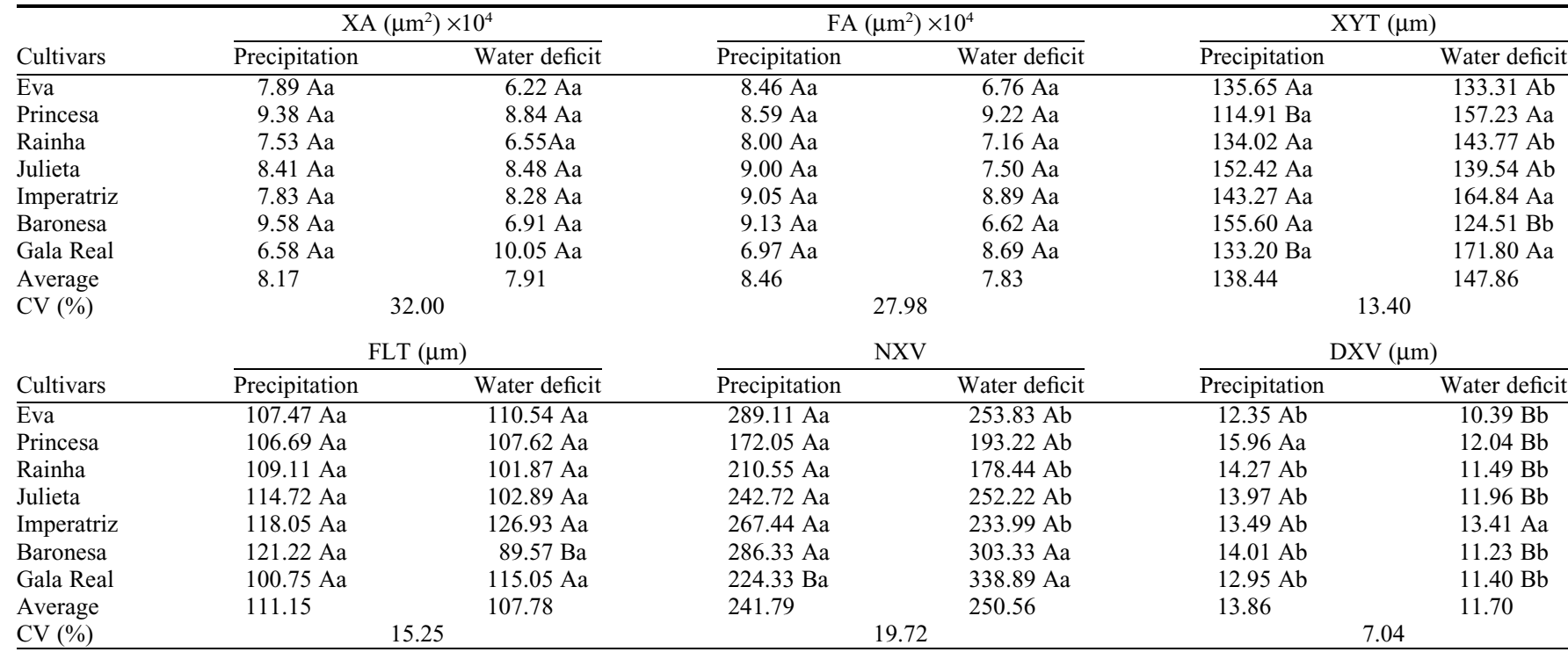

The means followed by the same letter, with lowercase in the columns and uppercase in the rows, do not differ from one another according to the Scott-Knott test at $5 \%$ probability.

Table 2. Thickness of the palisade parenchyma (PAP), thickness of the spongy parenchyma (SPP), thickness of the leaf blade (TLB), thickness of the adaxial epidermal (ADE), thickness of the abaxial epidermis (ABE), and thickness of the adaxial cuticle (ADC) in apple cultivars as estimated during the precipitation season (February) and the water deficit season (September) in 2016 and 2017.

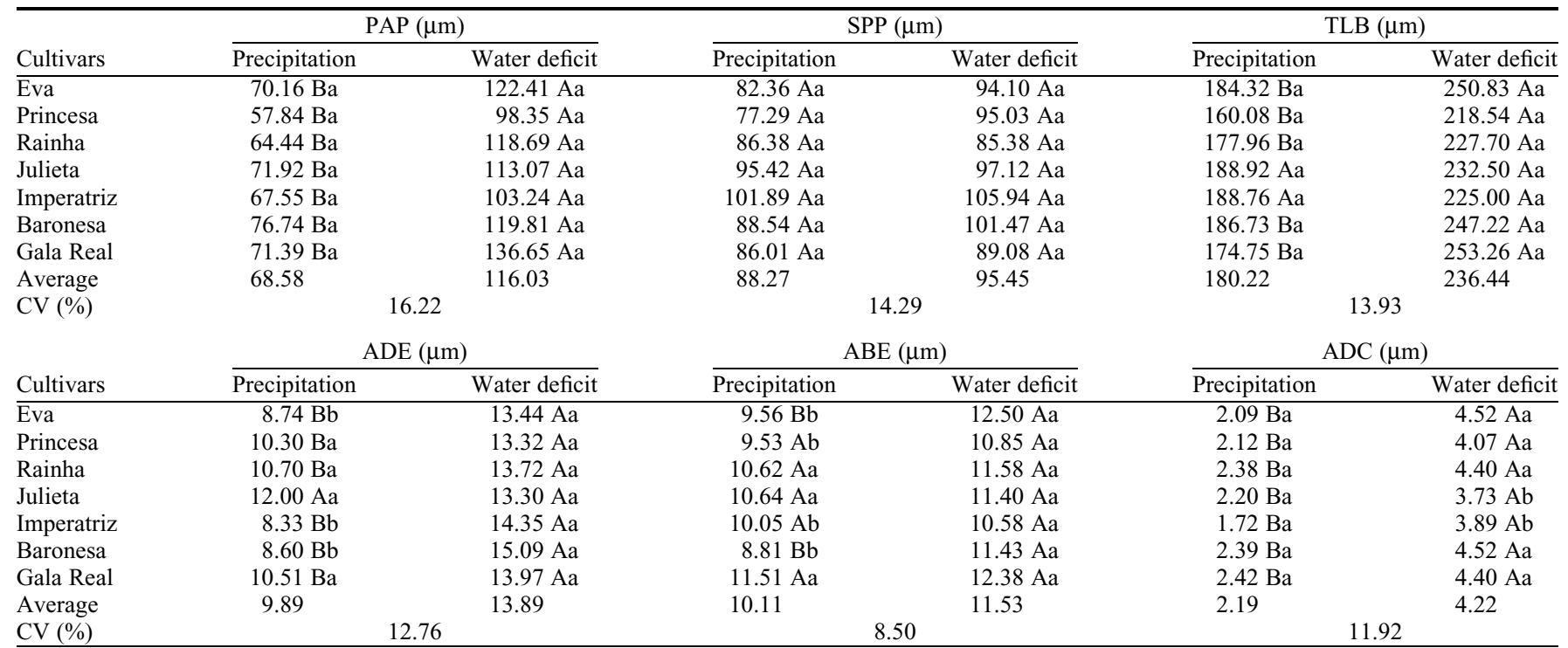

Means followed by the same letter, with lowercase in the columns and uppercase in the rows, do not differ from one another according to the Scott-Knott test at $5 \%$ probability. 
(1977) stated that narrower vessels have increased resistance to high pressures in the water column. Regarding these two evaluated characteristics, the best-adapted cultivar was the Gala Real and the least adapted was the Imperatriz. Oliveira et al. (2018) confirmed that almond cultivars with a higher frequency of transport vessels and smaller-diameter vessels are less susceptible to cavitation in the water column.

Studies have shown significant differences in the anatomical characteristics of leaves from coffee and olive trees under water deficit (Batista et al., 2010; Bosabalidis; Kofidis, 2002; Grisi et al., 2008; Viana et al., 2018), in Aegiphila sellowiana Cham. (Lamiaceae) when subjected to flooding (Medri et al., 2011), and with the shading of coffee plants (Baliza et al., 2012). Some researchers even use these characteristics for selecting progenies with drought tolerance, especially coffee (Coffea arabica) (Castanheira et al., 2016).

The thickness of the palisade parenchyma was higher in all cultivars during the water deficit season than during the precipitation season (Table 2). It should be emphasized that there was no difference between the cultivars studied after either of the two seasons. Batista et al. (2010) studied the role of the leaf anatomy and water potential in the tolerance to water deficits by coffee cultivars, and they found that the thickness of the palisade parenchyma was higher in cultivars with higher water potential. The palisade parenchyma is directly related to photosynthesis, and the greater development of this tissue may allow greater $\mathrm{CO}_{2}$ fixation with the opening of the stomata over a short period of time (Castro et al., 2009). This action increases the water use efficiency by reducing transpiration, thus providing the plant with greater chances to survive and reproduce under water deficit conditions (Jones, 1992).

Regarding the spongy parenchyma, there was no difference between the seasons and the cultivars; that is, when leaves were collected during the water deficit season, the internal leaf structure of the apple cultivars in subtropical regions exhibited thickening in the palisade parenchyma and no changes in the structure of the spongy parenchyma (Table 2). This tissue was closely related to the storage of $\mathrm{CO}_{2}$ in the leaf (Castro et al., 2009); therefore, plants seemed to have developed their palisade parenchyma at the expense of the spongy parenchyma to perform faster photosynthesis rather than store $\mathrm{CO}_{2}$ (Batista et al., 2010).

Most of the cultivars had thicker leaf blades during the water deficit season, except for the cultivars Julieta and Imperatriz (Table 2). The increase in the leaf blade thickness during the water deficit season was primarily due to the increase in the thickness of the palisade parenchyma and in the thickness of the adaxial cuticle. Kramer (1983) stated that water deficits are associated with increased leaf blade and cuticle thickness; this finding was supported in this study.

Cuticle thickening reduced cuticular transpiration, and this change in cuticle structure was observed in all the cultivars during the water deficit season (Fig. 2). The water deficit period was responsible for increasing the cuticle thickness by $55 \%$ relative to the precipitation period. Therefore, this variable together with the other anatomical modifications in the leaf are important changes that have been observed, and they may help the cultivars to decrease plant transpiration during periods of reduced water availability. Regarding the cuticle thickness of the cultivars, Eva, Princesa, Rainha, Baronesa, and Gala Real presented the highest mean cuticle thickness, suggesting that these cultivars may

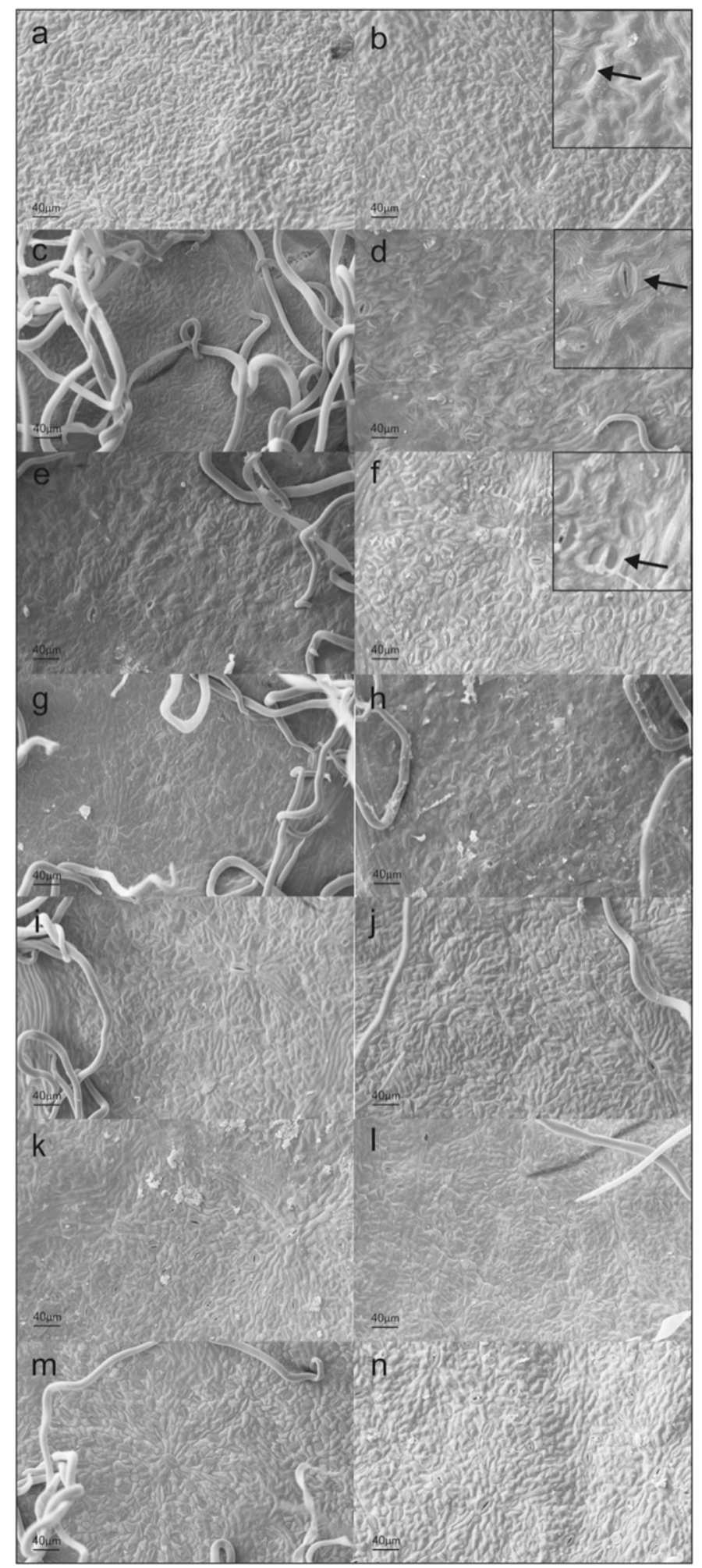

Fig. 2. Scanning electron microscopy image of different cultivars of Malus domestica (Rosaceae) during the two seasons: precipitation ( $\mathbf{A}, \mathbf{C}, \mathbf{E}, \mathbf{G}, \mathbf{I}, \mathbf{K}$, and $\mathbf{M})$ and water $\operatorname{deficit}(\mathbf{B}, \mathbf{D}, \mathbf{F}, \mathbf{H}, \mathbf{J}, \mathbf{L}$, and $\mathbf{N})$. (A and $\mathbf{B}$ ) Baronesa. (C and D) Eva. (E and $\mathbf{F}$ ) Gala Real. ( $\mathbf{G}$ and $\mathbf{H})$ Imperatriz. (I and $\mathbf{J})$ Julieta. (K and L) Princesa. (M and $\mathbf{N}$ ) Rainha. 
have better performance in areas with low rainfall because they have anatomical characteristics that allow these plants to reduce plant transpiration (Fig. 2).

Regarding the position of the stomata, the water deficit period caused the stomata to lie underneath the epidermal layer (Fig. 2B, D, and F). This result is important because the stomata located underneath the epidermal layer may help to reduce transpiration (Fig. 2).

There was an increase in the thickness of the adaxial epidermis cells for most of the cultivars during the water deficit period relative to the precipitation season, except for the Julieta cultivar (Table 2). The mean value for this variable during the water deficit season was $13.89 \mu \mathrm{m}$, whereas during the precipitation season it was $9.89 \mu \mathrm{m}$. During the precipitation season, the cultivars also differed in terms of the anatomical differentiation pattern in the adaxial epidermis, with Eva, Imperatriz, and Baronesa exhibiting the lowest thicknesses of $8.74,8.33$, and $8.60 \mu \mathrm{m}$, respectively. When the trees were under the influence of the water deficit, there was an increase in the thickness of the adaxial epidermis. Bosabalidis and Kofidis (2002) compared the effects of the water deficit on the leaf anatomy of olive cultivars, and they observed a decrease in the size of the cells and an increase in their number of $\approx 31.6 \%$ in the adaxial epidermis for plants under water deficit conditions compared with plants not subjected to this stress. According to Oertli et al. (1990), the smaller cell size and the lower sinuosity of the periclinal cell walls of the adaxial epidermal surface confer significant resistance to cell collapse under water deficit conditions.

Regarding the thickness of the abaxial epidermis, a difference was observed between the studied seasons for some cultivars. During the period of higher rainfall, the cultivars Eva, Princesa, Imperatriz, and Baronesa showed lower thickness values in the abaxial epidermis when compared with the water deficit period, and the Eva and Baronesa cultivars presented the highest values during the water deficit period for this parameter at 12.50 and $11.43 \mu \mathrm{m}$, respectively (Table 2).

Grisi et al. (2008) performed leaf anatomy evaluations of "catuaí" and "siriema" coffee plants under water stress and did not find a difference in the thickness of the leaf epidermis of the evaluated cultivars. The thickening of the epidermis and the palisade parenchyma may be able to increase resistance to water deficits and allow for the development of plants under these conditions by improving water relations and protecting the leaf tissue (Bacelar et al., 2004).

The cuticle has a lipidic nature, that is, a thicker cuticle can prevent excessive water loss through transpiration; therefore, it is an important mechanism of water deficit tolerance (Castro et al., 2009). As reported, the cuticle is an important cultivar adaptation factor in response to an environment with little water availability, as observed in the present study in which all the cultivars showed thickened cuticles during the water deficit season, which indicated an adaptive capacity (Table 2). During the precipitation season, the cultivars presented a mean cuticle thickness of $2.19 \mu \mathrm{m}$; however, during the water deficit period, the highest cuticle thickness values were $4.52 \mu \mathrm{m}$ for Eva, $4.40 \mu \mathrm{m}$ for Rainha, $4.52 \mu \mathrm{m}$ for Baronesa, and $4.40 \mu \mathrm{m}$ for Gala Real cultivars. Viana et al. (2018) evaluated the anatomical characteristics of leaves from coffee accessions, and they did not find differences in the thickness of the adaxial cuticle when comparing the water deficit and precipitation seasons.

Regarding the polar diameter of the stomata, only the Princesa cultivar showed a reduced diameter under water deficit conditions when compared with the precipitation season. During the precipitation season, the cultivars showed different results for this characteristic, with the Princesa and Julieta cultivars having the largest polar diameter for the stomata at 34.21 and $33.17 \mu \mathrm{m}$, respectively (Table 3). During the water deficit season, the cultivars presented similar results with a mean polar stomatal diameter of $30.03 \mu \mathrm{m}$. A similar result was also observed in some cultivars for the equatorial diameter of the stomata, with the cultivars Princesa, Julieta, and Baronesa showing smaller diameters during the water deficit season than during the precipitation season. Furthermore, during the precipitation season, these three cultivars presented different results than the other cultivars, with higher equatorial diameters for the stomata. During the water deficit period, as observed for the polar diameter of the stomata, the cultivars exhibited similar equatorial diameters in the stomata.

Grisi et al. (2008) and Queiroz-Voltan et al. (2014) also found distinct results for polar and equatorial stomatal diameters in coffee cultivars under water deficits. The polar/equatorial diameter ratio indicates the shape of the stomata, with higher values indicating the increased functionality of the stoma as a result of its ellipsoid shape (Castro et al., 2009). Therefore, even though some cultivars, such as Princesa and Baronesa, had modified polar and equatorial diameters, this change did not result in modified stomatal efficiency when the two seasons (precipitation and water deficit) were compared. The cultivars with the highest stomatal efficiency during the water deficit season relative to the precipitation season were Eva and Julieta, with the latter showing reduced equatorial diameter during the water deficit season. The variation in the response of the stomatal equatorial diameter indicated that this characteristic is less defined than the polar diameter as a consequence of the variation in cell turgidity, which is a determinant of the stomatal opening and closing movements (Taiz and Zeiger, 2004). Regarding 'Eva', no difference was observed for either diameter at different times; however, it presented lower mean polar and equatorial diameters during the precipitation season, which may have influenced the difference in stomatal efficiency.

The cultivars Rainha and Baronesa showed higher stomatal density during the precipitation season compared with the other cultivars (Table 3). During the water deficit season, the cultivars Princesa, Rainha, Baronesa, and Gala Real presented higher stomatal densities. Perhaps because the Eva cultivar showed a decrease in stomatal density during the precipitation season, this was the only cultivar that showed differences between the two seasons. A higher stomatal density may allow stomatal opening to occur within a shorter time, allowing for adequate $\mathrm{CO}_{2}$ uptake and preventing excessive transpiration; therefore, the plant may exhibit greater photosynthetic efficiency (Batista et al., 2010).

Castro et al. (2009) stated that environmental conditions such as water deficit alter

Table 3. Polar diameter of the stomata (POD), equatorial diameter of the stomata (EQD), stomatal functionality (FUN) (POD/EQD ratio), and stomatal density (DEN) of apple cultivars as estimated during the precipitation season (February) and the water deficit season (POD) and the equatorial diameter of the stomata (EQD) September) from 2016 and 2017.

\begin{tabular}{|c|c|c|c|c|c|c|c|c|}
\hline \multirow[b]{2}{*}{ Cultivars } & \multicolumn{2}{|c|}{ POD $(\mu \mathrm{m})$} & \multicolumn{2}{|c|}{ EQD $(\mu \mathrm{m})$} & \multicolumn{2}{|c|}{ FUN } & \multicolumn{2}{|c|}{ DEN (stomatal/mm²) } \\
\hline & Precipitation & Water deficit & Precipitation & Water deficit & Precipitation & Water deficit & Precipitation & Water deficit \\
\hline Eva & $29.03 \mathrm{Ab}$ & $29.99 \mathrm{Aa}$ & $18.31 \mathrm{Ab}$ & $16.41 \mathrm{Aa}$ & $1.58 \mathrm{Ba}$ & $1.82 \mathrm{Aa}$ & $284.99 \mathrm{Ab}$ & $156.54 \mathrm{Bc}$ \\
\hline Princesa & $34.21 \mathrm{Aa}$ & $29.44 \mathrm{Ba}$ & $20.59 \mathrm{Aa}$ & $17.56 \mathrm{Ba}$ & $1.66 \mathrm{Aa}$ & $1.68 \mathrm{Ab}$ & $266.94 \mathrm{Ab}$ & $345.20 \mathrm{Aa}$ \\
\hline Rainha & $29.98 \mathrm{Ab}$ & $31.65 \mathrm{Aa}$ & $18.08 \mathrm{Ab}$ & $18.63 \mathrm{Aa}$ & $1.65 \mathrm{Aa}$ & $1.70 \mathrm{Ab}$ & $412.10 \mathrm{Aa}$ & $386.68 \mathrm{Aa}$ \\
\hline Julieta & $33.17 \mathrm{Aa}$ & $33.94 \mathrm{Aa}$ & $20.64 \mathrm{Aa}$ & $18.07 \mathrm{Ba}$ & $1.60 \mathrm{Ba}$ & $1.88 \mathrm{Aa}$ & $275.62 \mathrm{Ab}$ & $276.96 \mathrm{Ab}$ \\
\hline Imperatriz & $27.15 \mathrm{Ab}$ & $30.16 \mathrm{Aa}$ & $17.32 \mathrm{Ab}$ & $18.19 \mathrm{Aa}$ & $1.56 \mathrm{Aa}$ & $1.66 \mathrm{Ab}$ & $290.53 \mathrm{Ab}$ & $286.33 \mathrm{Ab}$ \\
\hline Baronesa & $29.83 \mathrm{Ab}$ & $26.60 \mathrm{Aa}$ & $19.81 \mathrm{Aa}$ & $17.11 \mathrm{Ba}$ & $1.51 \mathrm{Aa}$ & $1.55 \mathrm{Ab}$ & $347.87 \mathrm{Aa}$ & $338.51 \mathrm{Aa}$ \\
\hline Gala Real & $27.01 \mathrm{Ab}$ & $28.41 \mathrm{Aa}$ & $17.26 \mathrm{Ab}$ & $17.90 \mathrm{Aa}$ & $1.56 \mathrm{Aa}$ & $1.59 \mathrm{Ab}$ & $297.04 \mathrm{Ab}$ & $367.95 \mathrm{Aa}$ \\
\hline Average & 30.06 & 30.03 & 18.86 & 17.70 & 1.59 & 1.70 & 310.73 & 308.31 \\
\hline CV $(\%)$ & \multicolumn{2}{|c|}{8.76} & \multicolumn{2}{|c|}{6.37} & \multicolumn{2}{|c|}{7.92} & \multicolumn{2}{|c|}{15.12} \\
\hline
\end{tabular}

Means followed by the same letter, with lowercase in the column and uppercase in the rows, do not differ from one another according to the Scott-Knott test at a $5 \%$ probability. 
the size and density of the stomata to assist the plant in tolerating this condition. In environments with less water availability, there is a decrease in the size of the stomata; therefore, there is less loss of water from the plant to the environment through transpiration and a simultaneous increase in stomatal density, which contributes to the balance of gas exchanges (Batista et al., 2010). This property can compensate for the leaf area loss that is commonly observed in plants under water deficit (Batista et al., 2010), as reported by Pinto et al. (2008), who observed a reduction in the leaf area and number of leaves in different species under water deficit.

When considering Eva, Baronesa, and Gala Real, for example, which presented the greatest number of anatomical changes under the influence of different water regimes, there was an increase in the stomatal density of the Eva cultivar under low water availability. However, this was not observed for the Baronesa and Gala Real cultivars (Fig. 3A and B). For these three cultivars, there was an increase in the thickness of the cuticle and the epidermis on both sides of the leaf. The highest mean thicknesses of the cuticle and epidermis were recorded on the adaxial surface (Fig. 3C and D).

Regarding the dorsiventral mesophyll, the water deficit promoted an increase in the thickness of the palisade parenchyma for these three cultivars, with no significant variations in the size and thickness of the spongy parenchyma. Consequently, the increase in the thickness of the cuticles, epidermis, and palisade parenchyma resulted in an increase in the thickness of the leaf blade as a whole (Fig. 3C and D).

During the evaluations of the vascular bundles under water deficit, the cultivars Eva and Baronesa presented increased xylem thickness, but they did not present a significant increase in the number of xylem vessels. However, an increase in this parameter was observed in the Gala Real cultivar (Fig. 3E and F).

These results indicated that these apple cultivars have the plasticity to modify some morpho-anatomical characteristics under water deficit, which favors their establishment in environments with both high and low water availability. Among others, Chagas et al. (2012) confirmed the adaptability of cultivars Eva and Baronesa under tropical conditions, thus corroborating the results of this work.
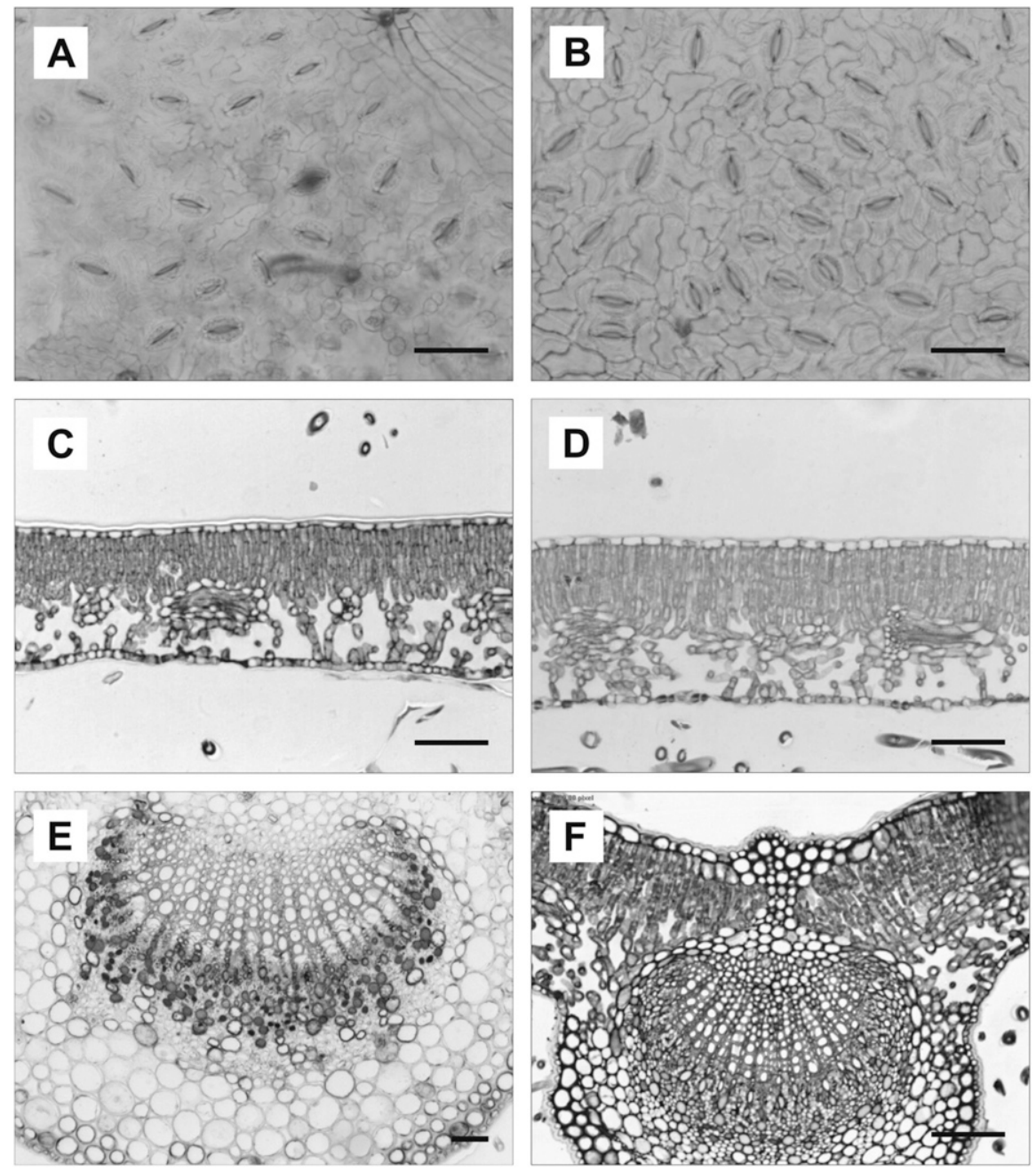

Fig. 3 Malus domestica (Rosaceae). (A) Paradermic view of the abaxial surface showing the presence of stomata from the Eva cultivar during the precipitation season; $b a r=25 \mu \mathrm{m}$. (B) Paradermic view of the abaxial surface showing the presence of stomata from the Eva cultivar during the water deficit season; bar $=25 \mu \mathrm{m}$. (C) Cross-section of the leaf mesophyll from the Eva cultivar during the precipitation season; bar $=50 \mu \mathrm{m}$. (D) Cross-section of the leaf mesophyll from the Eva cultivar during the water deficit season; bar $=50 \mu \mathrm{m}$. (E) Cross-section of the leaf midrib region of the Gala Real cultivar during the precipitation season; bar $=25 \mu \mathrm{m}$. (F) Cross-section of the leaf midrib region from the Gala Real cultivar during the water deficit season; bar $=50 \mu \mathrm{m}$.

Table 4. Dissimilarity measures among apple cultivars estimated during the precipitation season (February) and water deficit season (September) based on Gower's algorithm.

\begin{tabular}{|c|c|c|c|c|c|c|c|}
\hline \multirow[b]{2}{*}{ Cultivars } & \multicolumn{7}{|c|}{ Precipitation } \\
\hline & $\overline{\text { Eva }}$ & Princesa & Rainha & Julieta & Imperatriz & Baronesa & Gala Real \\
\hline Princesa & & 0 & 0.428 & 0.442 & 0.629 & 0.589 & 0.586 \\
\hline Imperatriz & & & & & 0 & 0.365 & 0.407 \\
\hline Baronesa & & & & & & 0 & 0.536 \\
\hline Gala Real & \multicolumn{6}{|c|}{ Water deficit } & 0 \\
\hline Eva & 0 & 0.504 & 0.380 & 0.393 & 0.600 & 0.374 & 0.453 \\
\hline Princesa & & 0 & 0.338 & 0.314 & 0.257 & 0.510 & 0.417 \\
\hline Rainha & & & 0 & 0.311 & 0.450 & 0.396 & 0.415 \\
\hline Julieta & & & & 0 & 0.362 & 0.470 & 0.505 \\
\hline Imperatriz & & & & & 0 & 0.544 & 0.473 \\
\hline Baronesa & & & & & & 0 & 0.432 \\
\hline Gala Real & & & & & & & 0 \\
\hline
\end{tabular}


evaluated during the precipitation season. They presented variations from 0.257 to 0.629 , indicating the broad genetic variability among the cultivars (Table 4). During the water deficit season, the pairs of genotypes from the seven cultivars presented variations from 0.257 to 0.600 (Table 4).

The environment had a great influence on the evaluated anatomical characteristics because the same pair of cultivars that were considered most dissimilar during the precipitation season was the one that was most similar during the water deficit season. Those that were most similar during the water deficit season were also most dissimilar during the precipitation season (Table 4). The cultivars Imperatriz and Princesa were the most dissimilar during the precipitation season (0.629) and the least dissimilar during the water deficit season (0.257) based on Gower's distance. In addition, the cultivars Imperatriz and Eva were the most similar during the precipitation season (0.257) and the most dissimilar during the water deficit season (0.600) according to Gower's distance. The three cultivars involved in this analysis were genetically very close because the Eva cultivar was produced from a cross between the Gala and Anna cultivars, the Princesa cultivar originated from a cross between the NJ 56 and Anna cultivars, and the Imperatriz cultivar originated from a somatic mutation of the Gala cultivar; therefore, this finding showed the effects of the environment on the cultivars. Viana et al. (2018) found genetic divergence in the anatomical characteristics of rust-resistant coffee plants. Castanheira et al. (2016) noted the potential use of anatomical characteristics in the selection of coffee progenies. The genetic variance was higher during the water deficit period, indicating that there was greater variability among the progenies during this period.

To study the genetic diversity using the UPGMA method, a cut-off distance of 0.50 was considered for both the precipitation and water deficit seasons based on the method of Mojena (1977), which led to the formation of two clusters in both seasons (Fig. 4). The dendrogram had high cophenetic values of 0.80 and 0.75 for the precipitation season and the water deficit season, respectively. However, the clusters of cultivars that formed during the two seasons were different. During the precipitation season, the cultivars Eva, Imperatriz, Julieta, Baronesa, Rainha, and Gala Real were grouped together in the first cluster, with only the Princesa cultivar in cluster II (Fig. 4A). This result confirmed what was observed during the analysis of genetic divergence, with great dissimilarity primarily occurring between the Imperatriz and Princesa cultivars. This finding was also evidenced by the principal component (PC) analysis (Fig. 5A), which showed that the Princesa cultivar is totally isolated from the others because it is the only one located on the positive side of PC1 and PC2.

As mentioned, the water deficit season also exhibited two distinct clusters. How-
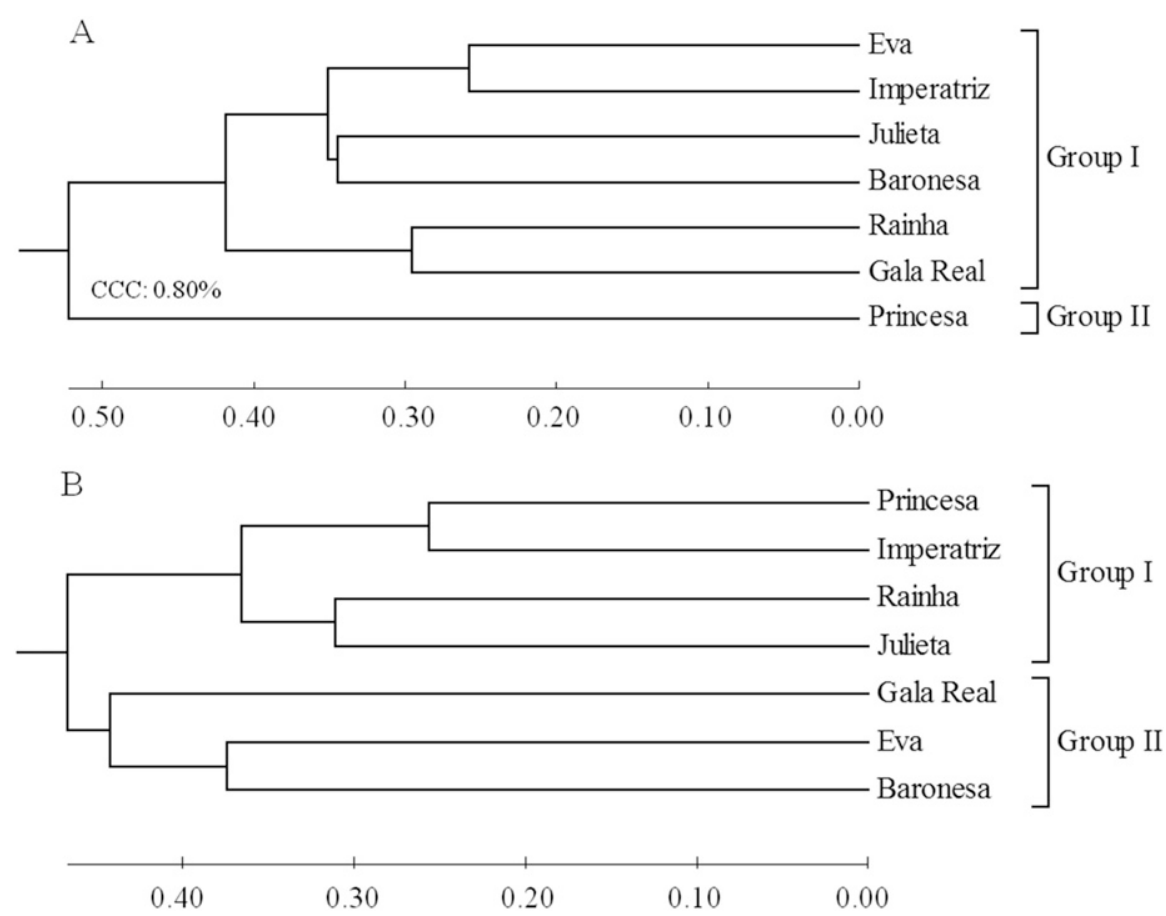

Fig. 4. Dendrogram of the clustering between apple tree cultivars as estimated during the precipitation season (February; A) and water deficit season (September; B) and obtained using the hierarchical unweighted pair-group method using an arithmetic mean method.

ever, cluster I included the cultivars Princesa, Imperatriz, Rainha, and Julieta, and cluster II comprised the Gala Real, Eva, and Baronesa cultivars (Fig. 4B). These results also confirmed the results that were obtained through the divergence analysis, during which the Imperatriz and Princesa cultivars were more similar during this season and were clustered together in the same group, whereas the Eva cultivar was in another cluster. This finding can also be confirmed by a PC analysis (Fig. 5B) in which the cultivars of cluster II are located on the negative side of $\mathrm{PC} 1$ and the cultivars of cluster I are located on the positive side of PC1.

During the dispersion analysis, the first two components explained $66.8 \%$ of the total cumulative variance during the precipitation season and $60.4 \%$ during the water deficit season (Fig. 5A and B). Regarding the precipitation period, the first component (PC1) explained $39.1 \%$ of the variance, and the second (PC2) explained $27.7 \%$ (Fig. 5A); however, regarding the water deficit period, $\mathrm{PC} 1$ explained $37.9 \%$ of the variance and PC2 explained $22.5 \%$ (Fig. 5B).

During the precipitation season, the anatomical characteristics of apple leaves that contributed most to the differentiation of the cultivars in PC1 were NXV, TLB, and XYT, with the Baronesa cultivar exhibiting the highest values for these characteristics. For PC2, the characteristics that contributed the most to cultivar differentiation were XA, FA, and EQD, with the Baronesa cultivar showing the highest XA and FA and the Julieta cultivar showing the highest EQD. During the water deficit season, the anatomical characteristics that most influenced the differentiation of the cultivars in PC1 were ADC, TLB, and DXV; the cultivars Eva, Baronesa, and Gala Real had the highest values for the first characteristic, the cultivars Eva, Baronesa, and Gala Real had the highest values for the second characteristic, and the Imperatriz cultivar had the highest value for the third characteristic. In the PC2 axis, the characteristics POD, FUN, and ADE were the primary contributors to the differentiation of the cultivars; Julieta exhibited the highest values for the first two characteristics and the Baronesa cultivar had the highest values for the third characteristic. Furthermore, Camposeo et al. (2011) found a correlation between the anatomical parameters of the leaves of wild and cultivated almond seedlings under water deficit conditions.

The PC analysis was important for classifying the cultivars according to the anatomical characteristics of apple leaves, and it corroborated the results found through the genetic divergence and cluster analyses. Castanheira et al. (2016) showed that during the water deficit season, the genetic variation in anatomical characteristics was greater; therefore, these results will be used to recommend new cultivars that showed greater leaf plasticity because of their possible satisfactory behavior in environments under water scarcity.

\section{Conclusions}

Genetic divergence among the apple cultivars was studied to determine anatomical 

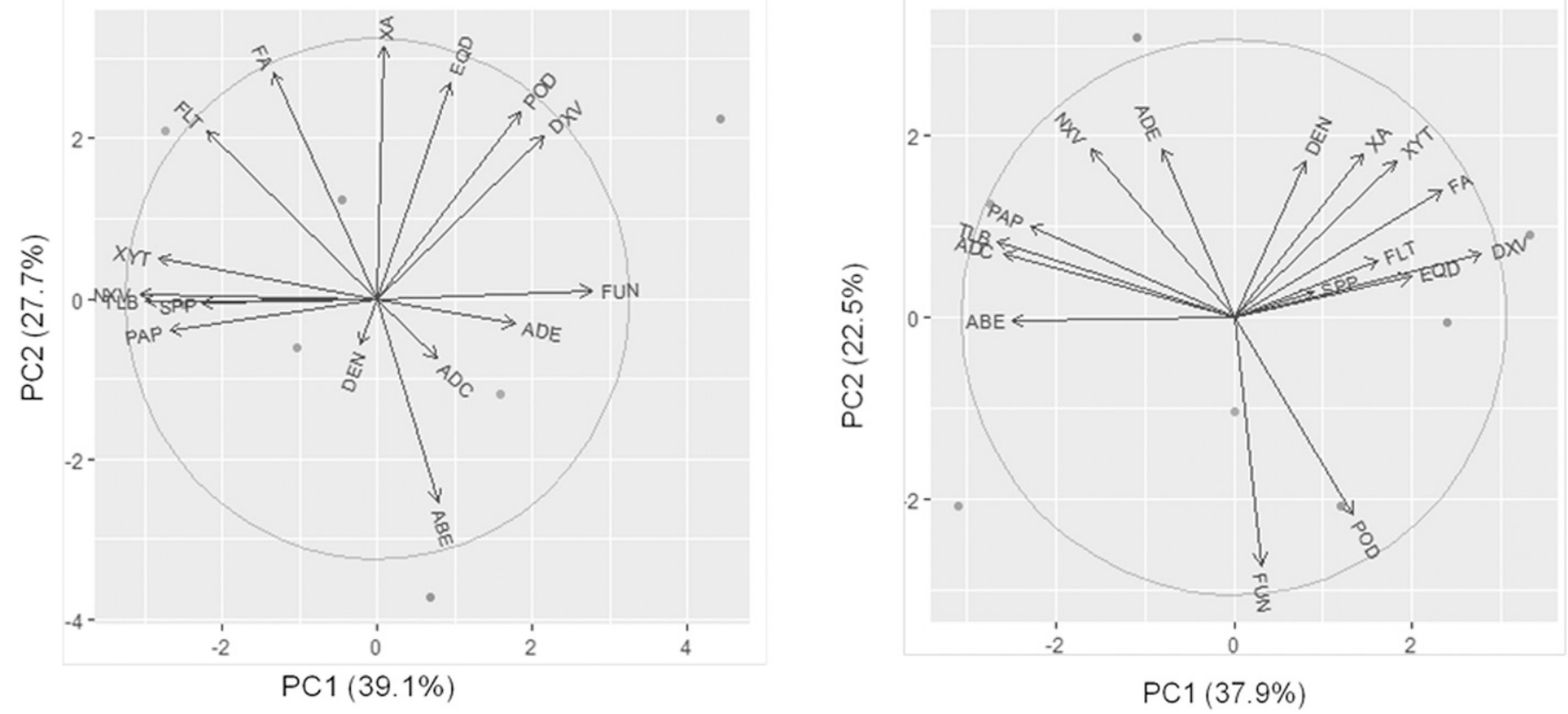

Fig. 5. Principal component analysis performed using anatomical characteristics of leaves from apple trees: (A) precipitation season (February) and (B) water deficit season (September).

characteristics. The Gala Real, Eva, and Baronesa cultivars have an internal leaf structure that is potentially adaptable to water deficit areas. The use of multivariate techniques related to anatomical characteristics showed the potential to be used in apple genetic breeding programs.

\section{Literature Cited}

Alvares, C.A., J.L. Stape, P.C. Sentelhas, J.L.M Gonçalves, and G. Sparovek. 2013. Köppen's climate classification map for Brazil. Meteorologische Zeitschrift 22:711-728.

Azevedo, A.M., V.C. Andrade Júnior, C.M. Oliveira, J.S.C. Fernandes, C.E. Pedrosa, M.F.S. Dornas, and B.M.C. Castro. 2013. Selection of lettuce genotypes for protected cultivation: Genetic divergence and importance of characters. Hort. Bras. 31:260-265.

Bacelar, E., C. Correia, J. Moutinho-Pereira, B. Gonçalves, J. Lopes, and J. Torres-Pereira. 2004. Sclerophylly and leaf anatomical traits of five field-grown olive cultivars growing under drought conditions. Tree Physiol. 24:233-239.

Baliza, D.P., R.L. Cunha, R.J. Guimarães, J.P. Barbosa, F.W. Ávila, and A. Passos. 2012. Physiological characteristics and development of coffee plants under different shading levels. Agraria 7:37-43.

Batista, L.A., R.J. Guimarães, F.J. Pereira, C.G. Rodrigues, and E.M.D. Castro. 2010. Anatomia foliar e potencial hídrico na tolerância de cultivares de café ao estresse hídrico. Cienc. Agron. 41:475-481.

Bosabalidis, A.M. and G. Kofidis. 2002. Comparative effects of drought stress on leaf anatomy of two olive cultivars. Plant Sci. 163:375-379.

Camposeo, S., M. Palasciano, G. Vivaldi, and A. Godini. 2011. Effect of increasing climatic water deficit on some leaf and stomatal param- eters of wild and cultivated almonds under Mediterranean conditions. Scientia Hort. 127:234-241.

Carlquist, S. 1977. Ecological factors in wood evolution: A loristic approach. Amer. J. Bot. 64:887-896.

Castanheira, D.T., T.T. Rezende, D.P. Baliza, J.M Guedes, S.P. Carvalho, R.J. Guimarães, and M.T.R. Viana. 2016. Potencial de utilização de características anatômicas e fisiológicas na seleção de progênies de cafeeiro. Coffee Sci. 11:374-385

Castro, E.M., F.J. Pereira, and R. Paiva. 2009 Histologia vegetal: Estrutura e função de órgãos vegetativos. UFLA, Lavras.

Cattivelli, L., R. Fulvia, W. Franz, E. Mazzucotelli, A. Mastrangelo, E. Francia, A. Tondelli, and A. Stanca. 2008. Drought tolerance improvement in crop plants: An integrated view from breeding to genomics. Field Crops Res. 105:1-14.

Chagas, E.A., P.C. Chagas, R. Pio, J.E. Bettiol Neto, J. Sanches, A.S. Carmo, P. Cia, M. Pasqual, and A.S. Carvalho. 2012. Production and quality attributes of apple tree cultivars in subtropical conditions at eastern of São Paulo state. Cienc. Rural 42:1764-1769.

Chartzoulakis, K., A. Patakas, and A.M. Bosabalidis. 1999. Changes in water relations, photosynthesis and leaf anatomy induced by intermittent drought in two olive cultivars. Environ. Exp. Bot. 42:113-120.

Cruz, C.D. 2013. Genes - A software package for analysis in experimental statistics and quantitative genetics. Acta Sci. Agron. 35:271-276.

Cruz, C.D., A. Regazzi, and P.C.S. Carneiro. 2004. Modelos biométricos aplicados ao melhoramento genético. 3rd ed. UFV, Viçosa.

Ebel, R.C., E.D. Proebsting, and R.G. Evans. 2001. Apple tree and fruit responses to early termination of irrigation in a semi-arid environment. HortScience 36:1197-1201.
Gower, J.C. 1971. A general coefficient of similarity and some of its properties. Biometrics 27:857-874.

Grisi, F.A., J.D.A. Alves, E.C. Castro, C. Oliveira, G. Biagiottis, and L.A. Melo. 2008. Leaf anatomical evaluations in 'Catuaí' and 'Siriema' coffee seedlings submitted to water stress. Cienc. Agrotec. 32:1730-1736.

Ivoglo, M.G., L.C. Fazuoli, A.C.B. Oliveira, P.B. Gallo, J.C. Mistro, M.B. Silvarolla, and M. TomaBraghini. 2008. Genetic divergence among robusta coffe progenies. Bragantia 67:823-831.

Johansen, D.A. 1940. Plant microtechnique. McGraw-Hill, New York

Jones, H.G. 1992. Plants and microclimate. 2nd ed. Cambridge University, New York.

Kramer, P.J. 1983. Water relations of plants. Agronomy (Basel) 70:630-634.

Kraus, J.E. and M. Arduin. 1997. Manual básico de métodos em morfologia vegetal. EDUR, Seropédica.

Medri, C., M.E. Medri, E.A. Ruas, L.A. Souza, P.S Medri, S. Sayhun, E. Bianchini, and J.A. Pimenta. 2011. Morpho-anatomy of vegetative organs in seedlings of Aegiphila sellowiana Cham. (Lamiaceae) subject to flooding. Acta Bot. Bras. 25:445-454.

Mojena, R. 1977. Hierarchical grouping methods and stopping rules: An evaluation. Comput. J. 20:359-363.

Moreira, R.M.P., J.M. Ferreira, L.S.A. Takahashi, M.E.C. Vanconcelos, L.C. Geus, and L. Botti. 2009. Agronomic potential and genetic divergence among genotypes of bush snap bean. Semin. Cienc. Agrar. 30:1051-1060.

Morgan, J.M. 1984. Osmoregulation and water stress in higher plants. Annu. Rev. Plant Physiol. 35:299-319.

Nunes, M.A., F. Catarino, and E. Pinto. 1989. Strategies for acclimation to seasonal drought in Ceratonia siliqua leaves. Physiol. Plant. $77: 150-156$. 
Oertli, J.J., S.H. Lips, and M. Agami. 1990. The strength of sclerophyllous cells to resist collapse due to negative turgor pressure. Acta Oecol. 11:281-289.

Oliveira, I., A. Meyerb, S. Afonso, and B. Gonçalves. 2018. Compared leaf anatomy and water relations of commercial and traditional Prunus dulcis (Mill.) cultivars under rain- fed conditions. Scientia Hort. 229:226-232.

Pinto, C.M., F.J.F.A. Távora, M.A. Bezerra, and M.C.M. Corrêa. 2008. Growth and root system distribution in peanuts sesame and castorbean under water deficiency deficit cycles. Cienc. Agron. 39:429-436.
Queiroz-Voltan, R.B., C.F. Nardin, L.C. Fazuoli, and M.T. Braghini. 2014. Leaf anatomy characterization of Coffea arabica plants at different seasonal periods. Biotemas 27:1-10.

Sircelj, H., M. Tausz, D. Grill, and F. Batic. 2005. Biochemical responses in leaves of two apple tree cultivars subjected to progressing drought. J. Plant Physiol. 162:1308-1318.

Sokal, R.R. and F.J. Rohlf. 1962. The comparison of dendrograms by objective methods. Taxon 11:33-40.

Taiz, L. and E. Zeiger. 2004. Fisiologia vegetal. 3rd ed. Artmed, Porto Alegre.
Viana, M.T.R., J.M. Guedes, J. Mauri, E.A. Silva, D.T. Castanheira, T.C.P. Gama, and R.J. Guimarães. 2018. Genetic variability in coffee genotypes resistant to rust used to impromemet programs. Sci. Agrár. Parana. 17:80-89.

Wright, P.R., J.M. Morgan, and R.S. Jessop. 1997. Turgor maintenance by osmoregulation in Brassica napus and B. juncea under field conditions. Ann. Bot. 80:313-319.

Zokaee-Khosroshahi, M., M. Esna-Ashari, A. Ershadi, and A. Imani. 2014. Morphological changes in response to drought stress in cultivated and wild almond species. Intl. J. Hort. Sci. Technol. 1:79-92. 